\title{
Piassava Fibers (Attalea funifera): NMR Spectroscopy of their Lignin
}

\author{
Adilson R. Gonçalves ${ }^{a *}$, Ulf Schuchardt ${ }^{b}$, Maria L. Bianchi ${ }^{b}$ and Antonio A. S. Curvelo ${ }^{c}$ \\ ${ }^{a}$ Departamento de Biotecnologia, Faculdade de Enghenharia Química de Lorena, \\ CP 116, 12600-000, Lorena - SP, Brazil \\ ${ }^{\mathrm{b}}$ Instituto de Química, Universidade Estadual de Campinas, CP 6154, \\ 13083-970, Campinas - SP, Brazil \\ ${ }^{\mathrm{c}}$ Instituto de Química de São Carlos, Universidade de São Paulo, CP 780, \\ 13560-970, São Carlos - SP, Brazil
}

\begin{abstract}
Lignina de piaçava (Attalea funifera) foi analisada por espectroscopia RMN de hidrogênio e carbono-13. A natureza HGS dessa lignina foi confirmada, mas unidades $p$-cumarato tambem estão presentes na estrutura da lignina. Os conteúdos de hidroxilas fenólicas e metoxilas por unidade fenilpropânica, determinados por $\mathrm{RMN}$ de ${ }^{1} \mathrm{H}$, foram 0,57 e 0,68 , respectivamente e estão em concordância com os dados obtidos por métodos clássicos. A pequena extensão da condensação da lignina $(35 \%)$ foi explicada pelo alto conteúdo de estruturas de álcool cinamílico, evidenciadas por $\mathrm{RMN}$ de ${ }^{13} \mathrm{C}$-DEPT. Uma fórmula $\mathrm{C}_{9}$ estendida foi determinada para a lignina da piaçava:$$
\mathrm{C}_{9.00} \mathrm{H}_{2.25}^{\mathrm{ar}} \mathrm{H}_{3.73}^{\mathrm{al}} \mathrm{O}_{0.89}(\mathrm{OH})_{0.69}^{\mathrm{ph}}(\mathrm{OH})_{0.86}^{\mathrm{al}}\left(\mathrm{OCH}_{3}\right)_{0.57}
$$

Lignin of piassava (Attalea funifera) was analyzed by ${ }^{1} \mathrm{H}$ - and ${ }^{13} \mathrm{C}-\mathrm{NMR}$ spectroscopy. The HGS-nature of this lignin was confirmed but $p$-coumarate units are also present in the lignin. Methoxyl and phenolic hydroxyl contents per phenylpropanic unit were determined by ${ }^{1} \mathrm{H}-\mathrm{NMR}$ spectroscopy to be 0.57 and 0.68 , respectively and are in agreement with wet chemistry methods. A small extent of lignin condensation ( $35 \%$ ) was explained by the high content of cinnamyl alcohol structures, evidenced by ${ }^{13} \mathrm{C}$-NMR-DEPT. An extended $\mathrm{C}_{9}$-formula for the piassava lignin was established to be$$
\mathrm{C}_{9.00} \mathrm{H}_{2.25}^{\mathrm{ar}} \mathrm{H}_{3.73}^{\mathrm{al}} \mathrm{O}_{0.89}(\mathrm{OH})_{0.69}^{\mathrm{ph}}(\mathrm{OH})_{0.86}^{\mathrm{al}}\left(\mathrm{OCH}_{3}\right)_{0.57}
$$

Keywords: piassava fibers, lignin, NMR-spectroscopy

\section{Introduction}

In a previous paper lignocellulosic material of piassava fiber (Attalea funifera, a palm tree) was characterized by chemical analysis and submitted to alkaline solvolysis in dioxane/water ${ }^{1}$. The results concerning the piassava lignin were remarkable. The Klason lignin content was unusually high (ca. 45\%) and the distillable oils, obtained by alkaline solvolysis in $40 \%$ yield (based on the raw material), consisted mainly of phenol, with some guaiacol, syringol and their alkyl derivatives. Methoxyl group analysis of the lignin showed a content of 0.54 OMe for each phenylpropane unit, suggesting that the lignin of piassava is rich in hydroxyphenyl units.

In this work piassava lignin was submitted to further in-depth analysis using NMR spectroscopy. ${ }^{1} \mathrm{H}$ - and ${ }^{13} \mathrm{C}-\mathrm{NMR}$ spectroscopy has been used as an alternative and

e-mail: adilson@debiq.faenquil.br non-degradative technique for the characterization of lignocellulosics. As shown in the literature ${ }^{2}$, hydrogen signals can be assigned in a ${ }^{1} \mathrm{H}-\mathrm{NMR}$ spectrum of acetylated lignin. The assignments of carbon signals in a ${ }^{13} \mathrm{C}-\mathrm{NMR}$ spectrum of lignin can also be improved by means of pulse sequence procedures such as DEPT. In the recent literature these techniques were used for monitoring production or reduction of lignin in pulps $^{3}$ and for characterizing residual and isolated lignins from pulps ${ }^{4}$. Other modern techniques such as ${ }^{1} \mathrm{H}_{-}{ }^{13} \mathrm{C}$ correlation spectra have been used for the characterization of grass lignins ${ }^{5}$. Since piassava lignin has not been well characterized until now, we present here the results of the NMR analysis of this lignin.

\section{Materials and Methods}

\section{Extraction of lignin from piassava fibers}

Piassava fibers obtained from palm tree (Attalea funifera), used in brooms, were exhautively washed with water and the 
extraction was performed with dioxan: $\mathrm{HCl} 2 \mathrm{~mol} \mathrm{~L}^{-1}(9: 1)$ at reflux temperature, for $5 \mathrm{~h}$. After evaporation of the solvent, extracted lignin was obtained and characterized for molecular weight distribution, FTIR and elementar analysis as described elsewhere ${ }^{1}$.

\section{Nuclear Magnetic Resonance}

The extracted piassava lignin was acetylated by a 1:1 pyridine/acetic anhydride solution at $50^{\circ} \mathrm{C}$ for $24 \mathrm{~h}$ in a sealed flask ${ }^{6}$.

The ${ }^{1} \mathrm{H}-\mathrm{NMR}$ spectrum of the acetylated lignin was recorded on a Bruker $300 \mathrm{MHz}$. The spectrum was measured at $24^{\circ} \mathrm{C}$ with $32 \mathrm{~K}$ data points and 128 scans, using $30 \mathrm{mg}$ of the sample dissolved in $1 \mathrm{~mL}$ of $\mathrm{CDCl}_{3}$ with TMS as internal standard. Pulse of $3.5 \mu$ s and relaxation delay $1 \mathrm{~s}$. The ${ }^{13} \mathrm{C}-\mathrm{NMR}$ spectrum of the non-acetylated lignin was recorded on a Bruker $300 \mathrm{MHz}$ at $24^{\circ} \mathrm{C}$ with $32 \mathrm{~K}$ data points and 19096 scans, using $30 \mathrm{mg}$ of the sample dissolved in $1 \mathrm{~mL}$ of DMSO (TMS as internal standard). Total spectrum measured by decoupling ${ }^{1} \mathrm{H}$ at acquisition time $(0.88 \mathrm{~s})$, using the POWGATE software (Inverse Gated Decoupling); irradiation pulse of $6.4 \mathrm{~ms}$, relaxation time of $5 \mathrm{~s}$. After the quantitative analysis, the DEPT (Distortionless Enhancement by Polarization Transfer) experiment was performed to assign the regions according to the type of carbon atom. The spectra were measured in the same spectrometer at $24^{\circ} \mathrm{C}$ with $32 \mathrm{~K}$ data points and 11000 scans and acquisition time $0.95 \mathrm{~s}$. Three basic subspectra were recorded with pulses of $45^{\circ}, 90^{\circ}$ and $135^{\circ}$ and the $\mathrm{CH}, \mathrm{CH}_{2}$ and $\mathrm{CH}_{3}$ pure subspectra were calculated and analyzed according to Chen and Robert ${ }^{2,7}$.

\section{Results and Discussion}

\section{${ }^{1} \mathrm{H}$-NMR spectrum of acetylated piassava lignin}

The analyses of molecular weight distribution and FTIR spectra of the extracted lignin published in the previous work, showed that no contaminants (such as tannins or other extractives) were present in the sample ${ }^{1}$.

The results of the semiquantitative analysis of the ${ }^{1} \mathrm{H}-\mathrm{NMR}$ spectrum are shown in Table 1, where the hydrogen signals and areas are subdivided into the corresponding regions.

From the elemental analysis of extracted piassava ${ }^{1}$ $(54.5 \% \mathrm{C} ; 5.84 \% \mathrm{H} ; 0.52 \% \mathrm{~N})$, and subtracting the holocellulose content $\left(54.73 \%\right.$ measured as $\left.\mathrm{C}_{6} \mathrm{H}_{10} \mathrm{O}_{5}\right)$, we obtained the following atomic ratio for the piassava lignin: $\mathrm{C}_{2.51} \mathrm{H}_{2.42} \mathrm{O}_{0.79}$, where the nitrogen content was neglected and the oxygen content calculated by difference. In lignin chemistry the empirical formula of the macromolecule is commonly given as a hypothetical hydroxyphenyl structure unit. This is known as the $\mathrm{C}_{9}$-formula, with 6 carbon atoms at the benzene ring plus three carbon atoms of the propyl side-chain. Besides these 9 carbon atoms, only the carbon atom of the methoxyl units $\left(-\mathrm{OCH}_{3}\right)$ is present in the macromolecule. For the calculation of the $\mathrm{C}_{9}$-formula the first step is to determine the methoxyl content and subtract it from the total carbon. This determination is easily made either by wet chemistry or by integration of the hydrogen signal of the ${ }^{1} \mathrm{H}-\mathrm{NMR}$ spectrum, since the methoxyl region is well defined.

The integration of the hydrogen signals (Table 1) results in a total area of 203.2 arbitrary units which corresponds to the 2.42 protons in the above-given ratio. The integration of the methoxyl region $(\delta 3.55-3.95)$ results in 0.15 methoxyl units $(0.44$ hydrogen atoms divided by 3 hydrogen atoms per methoxyl group). Subtracting this value from the total carbon and oxygen atoms as well as subtracting the hydrogen atoms corresponding to the methoxyl units, we can establish a new relation: $\mathrm{C}_{2.36}$ $\mathrm{H}_{1.98} \mathrm{O}_{0.64}\left(\mathrm{OCH}_{3}\right)_{0.15}$. Making the carbon atoms to 9.00 , the $\mathrm{C}_{9}$-formula was calculated to: $\mathrm{C}_{9.00} \mathrm{H}_{7.53} \mathrm{O}_{2.44}$ $\left(\mathrm{OCH}_{3}\right)_{0.57}$ (Table 1). The calculated value for $\mathrm{OCH}_{3}$ per $\mathrm{C}_{9}$ unit is 0.57 which is in agreement with the value of 0.54 obtained in the previous paper ${ }^{1}$. These values are

Table 1. ${ }^{1}$ H-NMR data of the acetylated piassava lignin (Area and total protons are divided into regions according to Chen and Robert ${ }^{2}$ ).

\begin{tabular}{|c|c|c|c|c|}
\hline \multirow{2}{*}{$\begin{array}{c}\text { region } \delta \\
(\mathrm{ppm})\end{array}$} & \multirow[t]{2}{*}{ attribution } & \multirow{2}{*}{$\begin{array}{c}\text { area } \\
\text { (arbitrary units) }\end{array}$} & \multicolumn{2}{|c|}{ hydrogens } \\
\hline & & & $\begin{array}{l}\text { in atom ratio } \\
\mathrm{C}_{2.51} \mathrm{H}_{2.42} \mathrm{O}_{0.79}\end{array}$ & $\begin{array}{ccc} & \text { in formula } \\
\mathrm{C}_{9.00} & \mathrm{H}_{7.53} & \mathrm{O}_{2.44}\left(\mathrm{OCH}_{3}\right)_{0.57}\end{array}$ \\
\hline $9.00-12.00$ & Carboxylic acids and aldehydes & 0 & - & \\
\hline $6.25-7.90$ & Aromatic region & 49.5 & 0.590 & 2.25 \\
\hline $5.75-6.25$ & Noncyclic benzylic region & 6.0 & 0.071 & 0.27 \\
\hline $5.20-5.75$ & Cyclic benzylic region & 5.5 & 0.065 & 0.25 \\
\hline $3.95-5.20$ and $2.50-3.55$ & Aliphatic region & 38.0 & 0.453 & 1.73 \\
\hline $3.55-3.95$ & Methoxyl & 37.5 & 0.447 & $1.70=0.57 \mathrm{OMe}$ \\
\hline $2.20-2.50$ & Aromatic acetoxyl region $*$ & 15.2 & 0.181 & 0.69 \\
\hline $1.60-2.20$ & Aliphatic acetoxyl region $*$ & 19.0 & 0.226 & 0.86 \\
\hline \multirow[t]{2}{*}{$<1.60$} & Nonoxygenated aliphatic region & 32.5 & 0.387 & 1.48 \\
\hline & sum & 203.2 & 2.42 & \\
\hline
\end{tabular}


also in agreement with those obtained by Berns et al. ${ }^{8}$ from analytical pyrolysis of piassava fibers. These authors found a $\mathbf{H} / \mathbf{G} / \mathbf{S}$ ratio of 51/40/9, which correponds to an average methoxyl content of $0.58 \mathrm{OCH}_{3} / \mathrm{C}_{9}$ unit.

The condensation degree of the lignin can be calculated from the methoxyl content and the ${ }^{1} \mathrm{H}-\mathrm{NMR}$ spectrum. For each $\mathrm{C}_{9}$ unit a maximum of 4 aromatic hydrogen atoms is expected, since the carbons at positions 1 and 4 are linked to the propyl chain and to the phenolic hydroxyl/ ether linkage, respectively. Some of the aromatic positions are occupied by methoxyl groups and for the piassava lignin a maximum of 3.43 aromatic hydrogens ( 4.00 minus $\left.0.57 \mathrm{OCH}_{3}\right)$ is expected. The aromatic region $(\delta 6.25$ to 7.90) corresponds to 2.25 hydrogens per $\mathrm{C}_{9}$ unit, thus allowing the determination of the condensation degree (34\%) by the difference to the maximum aromatic hydrogens. This value is similar to that of lignins obtained by steam explosion, which ranges from $38 \%$ to $41 \%$. The conden-sations are mostly due to 5-5 and $\beta-1$ linkages between phenylpropanic units.

Determination of phenolic hydroxyl groups by NMR $\left(0.69 / \mathrm{C}_{9}\right.$, Table 1$)$ is also in agreement with the chromatographic method $\left(0.72 / \mathrm{C}_{9}\right)^{1}$. Additionally, the aliphatic $\mathrm{OH}$ groups amount to 0.86 per $\mathrm{C}_{9}$ unit. Thus the $\mathrm{C}_{9}$ formula can be expanded to

$$
\mathrm{C}_{9.00} \mathrm{H}_{2.25}^{\mathrm{ar}} \mathrm{H}_{3.73}^{\mathrm{al}} \mathrm{O}_{0.89}(\mathrm{OH})_{0.69}^{\mathrm{ph}}(\mathrm{OH})_{0.86}^{\mathrm{al}}\left(\mathrm{OCH}_{3}\right)_{0.57}
$$

The amount of aldehyde and acidic protons is negligible (signal above $\delta 9$ ). This corresponds to a small content of terminal $\gamma$-carbonyl and carboxyl groups, showing that most carbonyl groups are located in $\alpha$ and $\beta$ positions of the propyl chains.

\section{${ }^{13} C$-NMR spectrum of the piassava lignin}

The ${ }^{13} \mathrm{C}-\mathrm{NMR}$ spectrum of the extracted piassava lignin is shown in Figure 2. It has characteristic $\mathbf{H}$ signals found at $\delta 161.5,131.3,116.0$ and $121.3^{2}$ and also typical $p$-coumarate signals in the region around $\delta 150$. Furthermore these signals have the highest intensities confirming the high $\mathbf{H}$ content of this lignin, evidenced by other techniques, or the high incorporation of $p$-coumarate units as attached moieties, as described for other lignins ${ }^{10,11}$.

The non-aromatic region $(\delta 50-103)$ has a small intensity. Since each $\mathrm{C}_{9}$-unit contains 6 aromatic and 3 aliphatic carbons, the integration of the non-aromatic region is expected to amount to about half of that of the aromatic region. In order to verify the presence of aliphatic structures such as cinnamic acids in the aromatic region, a DEPT spectrum was recorded to separate $\mathrm{CH}, \mathrm{CH}_{2}$ and $\mathrm{CH}_{3}$ signals (Figure 2$)$. The aromatic region $(\delta$ 103-160) is only contaminated by $\mathrm{C}-\alpha$ and $\mathrm{C}-\beta$ of cinnamyl-type structures, and the integration of these signals $(\delta 122-130.5$ and $\delta 151.5$ to 154.5 , respectively) must be considered to be part of the non-aromatic region (carbons of propyl side chain). With respect to the $\mathrm{C}_{9}$-formula the aromatic region must correspond to 6 carbon atoms. The total integration of this region ( $\delta 103$ to 155$)$ is 72.0 arbitrary units which corresponds to 12.0 arbitrary units/carbon atom. Table 2 shows the results of the application of this factor to all regions of the ${ }^{13} \mathrm{C}-\mathrm{NMR}$ spectrum.

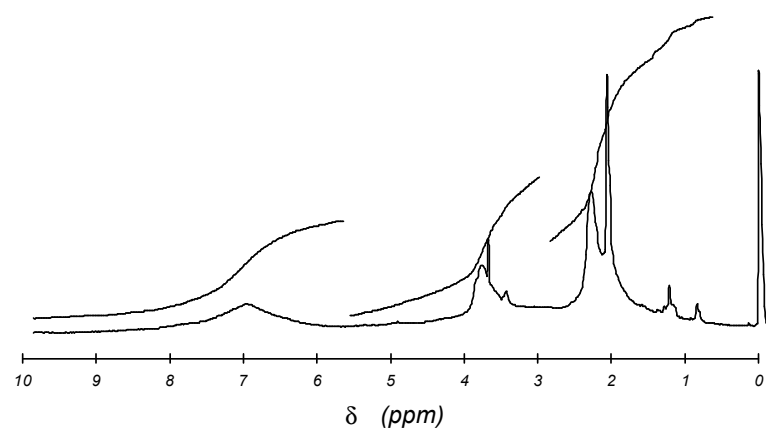

Figure 1. ${ }^{1} \mathrm{H}-\mathrm{NMR}$ spectrum of acetylated piassava lignin.

Some information is first obtained by the integration of the region between $\delta 103-107$, which corresponds exclusively to C-2 and C-6 in s units (Table 2) and has an integration of 2.5 arbitrary units corresponding to 0.21

Table 2. ${ }^{13} \mathrm{C}$-NMR data of piassava lignin lignin (Area and total carbons are divided into regions according to Chen and Robert ${ }^{2}$ ).

\begin{tabular}{lccc}
\hline $\begin{array}{c}\text { chemical shift range } \\
(\delta \text { in } \mathrm{ppm})\end{array}$ & region & $\begin{array}{c}\text { area } \\
\text { (arbitrary units })\end{array}$ & $\begin{array}{c}\text { carbon atoms per } \\
\text { benzene ring }\end{array}$ \\
\hline $\begin{array}{l}162.0-154.5 \text { and } \\
151.5-130.5\end{array}$ & Aromatic quaternary C & 39.0 & 3.25 \\
$122.0-103.0$ & Aromatic tertiary C & 33.0 & 2.75 \\
$107.0-103.0$ & Syringyl C-2/C-6 & 2.5 & 0.21 \\
$58.0-55.0$ & Methoxyl & 8.0 & 1.50 \\
$154.5-151.5$ and & Side chain cinnamyl structures & 18.0 & 1.08 \\
$130.5-122.0$ & Side chain other non-aromatics & 13.0 & 0.06 \\
$99.0-58.0$ and & Carbonyls & 0.7 & \\
$55.0-51.0$ & & & \\
$195.0-190.0$ & & & \\
\hline
\end{tabular}


C-2 and C-6 per aromatic ring. This is equivalent to 0.105 $\mathbf{S}$ units per $\mathrm{C}_{9}$ unit or $10.5 \% \mathbf{S}$ units in piassava lignin. Analytical pyrolysis furnished a similar value of $9 \%^{8}$.

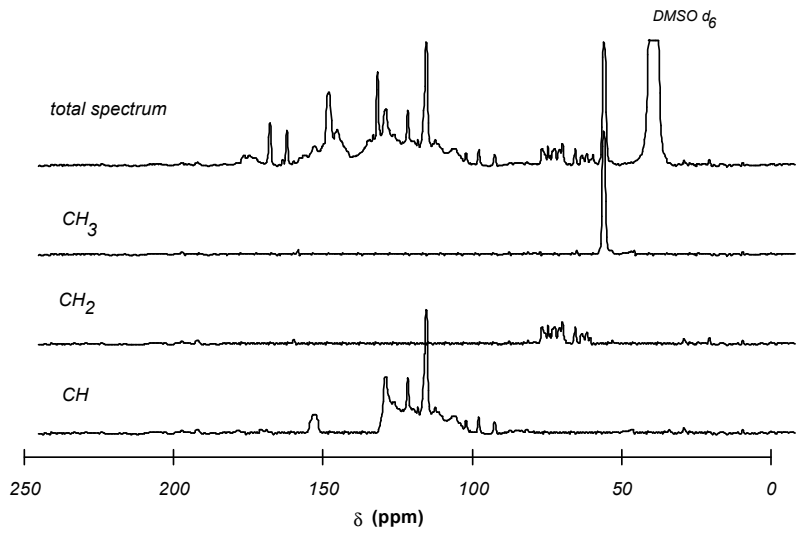

Figure 2. ${ }^{13} \mathrm{C}-\mathrm{NMR}$ spectrum and $\mathrm{CH}_{3^{-}}, \mathrm{CH}_{2^{-}}, \mathrm{CH}$-subspectra of piassava lignin.

Methoxyl content is calculated by integration of the $\delta 55$ to 58 region, giving a total area of 8.0 arbitrary units, which correspond to $0.67 \mathrm{OMe} / \mathrm{C}_{9}$. This value is $24 \%$ higher than the $0.54 \mathrm{OCH}_{3}$ per $\mathrm{C}_{9}$ unit found by wet chemistry methods ${ }^{1}$.

A close analysis was performed with respect to the aromatic region. Table 2 shows that the integration of $\mathrm{CH}$ signals (tertiary carbons) amounts to 2.75 carbons. A corresponding analysis of ${ }^{1} \mathrm{H}-\mathrm{NMR}$ spectrum revealed only 2.25 hydrogens for this region. A higher intensity for the tertiary carbons could be attributed to the Nuclear Overhauser Effect, although the difference is high (22\%). The values obtained from the ${ }^{1} \mathrm{H}-\mathrm{NMR}$ analysis are accepted as being correct.

The aliphatic region containing cinnamyl structures has an unusual integration area, corresponding to 1.5 carbons per $\mathrm{C}_{9}$ unit. This accounts for the small conden-sation of this lignin. It seems that the original structures were preserved in the piassava lignin biosynthesis, in spite of its high $\mathbf{H}$ content.

\section{Conclusions}

${ }^{1} \mathrm{H}$ - and ${ }^{13} \mathrm{C}-\mathrm{NMR}$ spectroscopy was used in this work for piassava lignin characterization and good results were obtained. Information about methoxyl $\left(0.57 \mathrm{OCH}_{3}\right.$ per
$\mathrm{C}_{9}$ unit) and phenolic hydroxyl $\left(0.69 \mathrm{OH}^{\mathrm{ph}}\right.$ per $\mathrm{C}_{9}$ unit) contents agree with those obtained by other methods. An extended $\mathrm{C}_{9}$-formula was obtained $\mathrm{C}_{9.00} \mathrm{H}_{2.25}^{\mathrm{ar}} \mathrm{H}_{3.73}^{\mathrm{al}} \mathrm{O}_{0.89}(\mathrm{OH})_{0.69}^{\mathrm{ph}}(\mathrm{OH})_{0.86}^{\mathrm{al}}\left(\mathrm{OCH}_{3}\right)_{0.57}$. The piassava lignin has a HGS nature, with high content of $p$-coumarate, and the presence of cinnamyl alcohol structures was evidenced by ${ }^{13} \mathrm{C}-\mathrm{NMR}$. The degree of piassava lignin condensation is low (34\%), which explains its high reactivity under basic hydrolysis conditions.

\section{Acknowledgements}

Financial support from FAPESP and CNPq are acknowledged. The authors thank M. E. M. Coelho for technical assistance.

\section{References}

1. Schuchardt, U.; Bianchi, M. L.; Gonçalves, A. R.; Curvelo, A. A. S.; Biscolla, F. C.; Peres, L. O. Cellul. Chem. Technol. 1995, 29, 705.

2. Chen, C. L.; Robert, D. In Methods in Enzimology, 161, Wood, W. A.; Kellog, S. T., Eds.; Academic Press; New York, 1988, p. 137.

3. Labidi, A.; Robert, D.; Pla, F. Holzforschung 1993, 47, 213.

4. Pan, X.; Lachenal, D.; Neirinck, V.; Robert, D. J. Wood Chem. Technol. 1994, 14, 483.

5. Galkin, S.; Ärmmälahti, E.; Kilpeläinen, I.; Brunow, G.; Hatakka, A. Holzforschung 1997, 51, 130.

6. Chen, C. L. In Methods in Lignin Chemistry, Lin, S.Y; Dence, C.W., Eds.; Springer Verlag; Berlin, 1992, p. 409.

7. Robert, D. In Methods in Lignin Chemistry, Lin, S.Y.; Dence, C.W., Eds.; Springer Verlag; Berlin, 1992, p. 250.

8. Berns, J; Meier, D. and Faix, O. Analytical pyrolysis of piassava, unpublished results, personal communication.

9. Silva, F. T., Ph. D. Thesis, State University of Campinas, Campinas, Brazil, 1995.

10. Ralph, J.; Hatfield, D. J. Agric. Food Chem. 1991, 39, 1426.

11. Ralph, J.; Hatfield, R.D.; Quideau, S.; Helm, R.F.; Grabber, J.H.; Jung, H. -J. G. J. Am. Chem. Soc. 1994, 116, 9448.

Received: July 14, 1999

Published on the web: August 31, 2000

FAPESP helped in meeting the publication costs of this article. 